\title{
Celso Furtado: o dilema do subdesenvolvimento e o fator político na formação nacional
}

\author{
Adenilson Ferreira de Souza*
}

\begin{abstract}
Resumo
O objetivo principal deste artigo é analisar a noção de subdesenvolvimento e o fator político na formação nacional, tendo como suporte referencial o pensamento de Celso Furtado. É ele o pensador que melhor serve à análise da realidade brasileira e sul-americana dos anos 50 e 60. Detentor de experiência nos campos da política, como Ministro do Planejamento, e da administração pública, e como diretor da Sudene, Furtado é quem melhor compreende o subdesenvolvimento, entendendo-o como um fenômeno histórico resultante da revolução industrial inglesa do século XVIII, e não como um estágio pelo qual as economias atrasadas necessitam passar e do qual devam arrancar-se. No caso brasileiro, a tomada de consciência do subdesenvolvimento na década de 1960, altera o rumo da política e da economia nas décadas subsequentes. Entretanto, uma reminiscência da história política e econômica do país evidencia uma relação de interdependência entre esses dois setores da sociedade brasileira, desde o período colonial. O pensamento de Celso Furtado permite-nos evidenciar, além de uma análise profunda da relação entre economia e política, o fator político na formação da identidade nacional.
\end{abstract}

Palavras-chave: Subdesenvolvimento; Fator político; Formação nacional.

Entre os principais pensadores brasileiros que trataram da matriz social, política, econômica, histórica e cultural do país, Celso Furtado (1920-2004), não sem razão, ocupa lugar de extrema importância para a compreensão de dilemas como o do subdesenvolvimento e da formação e preservação da identidade nacional.

A consolidação do pensamento econômico no Brasil está indissoluvelmente ligada a Celso Furtado. As obras Formação econômica do Brasil (1959) e Desenvolvimento e subdesenvolvimento (1961) definem um método analítico ${ }^{1} \mathrm{e}$ abarcam, com pertinência, os determinantes da dinâmica econômica brasileira. Embora

\footnotetext{
* Mestre em Relações Internacionais pela Pontifícia Universidade Católica de Minas Gerais. Licenciado em História Pela Universidade Católica de Pernambuco e Bacharel em Filosofia e Teologia pela Faculdade Jesuíta de Filosofia e Teologia.

${ }^{1} \mathrm{O}$ método adotado por Celso Furtado para a análise da sociedade brasileira e sul-americana, em sua dimensão social, política e econômica, é o histórico-estrutural, de uso corrente pelos analistas "clássicos" da Comissão Econômica para a América Latina - CEPAL.
} 
o epicentro de sua reflexão esteja na dimensão econômica, a moldura de sua argumentação é feita pelo seu pensamento político, evidenciada exemplarmente em $A$ pré-revolução brasileira (1962). Não apenas pela vastidão de suas obras, mas, sobretudo, pela profundidade de suas análises, "Furtado converte-se em demiurgo do Brasil". (OLIVEIRA, 1983, p.13)

A partir das influências teóricas das Ciências Humanas e da Economia, Celso Furtado formula uma narrativa de sentido da nação. A preocupação com um projeto para o Brasil perpassa todo o pensamento furtadiano. A perspectiva interdisciplinar com que procurou abordar suas teses permite-nos analisar sua obra como paradigmática também para a História, a Sociologia, a Ciência Política, e não apenas para a Ciência Econômica.

Em ensaio intitulado "A trajetória intelectual de Celso Furtado", Juarez Guimarães assegura-nos que: "Não nos enganemos: se a angulação [da argumentação] é econômica, a problemática é civilizatória e deriva, pois para a sociologia [a formação social], para a política [centros de decisão de poder] e para a cultura [autonomia ou alienação].” (GUIMARÃES, 2000, p.18)

O pensamento de Celso Furtado recebe contornos inteiramente novos a partir das formulações da Comissão Econômica para a América Latina - CEPAL - da Organização das Nações Unidas - ONU -, a qual, desde o Manifesto latino-americano (1949), também conhecido como o Manifesto dos periféricos, elaborado pelo seu primeiro diretor, o argentino Raúl Prebisch, ${ }^{2}$ chamou a atenção para o falso senso de universalidade da teoria econômica elaborada nos países desenvolvidos.

Ao cunhar a relação centro-periferia, Prebisch contesta a imagem de harmonia e cooperação mundial sugerida pelos intérpretes neoclássicos da Teoria da Vantagem Comparativa - TVC -, como Paul A. Samuelson, ${ }^{3}$ aplicando-a indiscriminadamente em qualquer contexto e realidade. David Ricardo mostra, com sua teoria, que não é

\footnotetext{
${ }^{2}$ Raúl Prebisch notorizou-se no campo da ciência econômica ao adotar uma perspectiva de análise da realidade sul-americana distinta e contestatória da teoria do desenvolvimento então vigente na Europa Ocidental e nos EUA, de textura liberal, baseada na Teoria da Vantagem Comparativa de David Ricardo. Entre as principais contribuições do pensamento de Prebisch para a reavaliação das teorias econômicas e das ciências sociais latinoamericanas destacam-se a adoção de um ponto de inflexão na trajetória teórica latinoamericana [isto é, pensar o subdesenvolvimento como uma resultante do comércio internacional] e a denúncia dos efeitos desestabilizadores da política do livre comércio imposta pelos países ricos "centrais" - sobre os países pobres - "periféricos".

3 A obra que melhor expressa a vinculação de Paul Anthony Samuelson à Teoria da Vantagem Comparativa é Fundamentos da análise econômica, de 1983; publicada originalmente em 1941, quando apresentada à Comissão do Prêmio David A. Wells, da Universidade de Harvard. Samuelson foi o primeiro norteamericano a ganhar o Nobel de Economia.
} 
necessário a existência da vantagem absoluta, como defende a teoria de Adam Smith, para que a especialização e o comércio sejam vantajosos. Ricardo afirma que, ainda que uma nação apresentasse desvantagem absoluta na produção de ambas as mercadorias em relação a outra nação, o comércio seria vantajoso, desde que ela se especializasse na produção e exportação do bem em que sua vantagem absoluta fosse maior. Além disso, deveria importar a mercadoria em que sua vantagem absoluta fosse menor. Isso significa que se "os EUA superam o Brasil tanto na produção de milho quanto na produção de tecidos, mesmo assim, valerá a pena para os Estados Unidos se concentrarem apenas na produção de milho". Em termos numéricos, "nos Estados Unidos, para se obter $1 \mathrm{~kg}$ de milho teríamos de deixar de produzir $0,5 \mathrm{~m}$ de tecido. Já no Brasil, o custo é de 1 para 1 , pois para se obter $1 \mathrm{~kg}$ de milho $1 \mathrm{~m}$ de tecido deixará de ser produzido". Importante ressaltar que "1 $\mathrm{m}$ de tecido custa $2 \mathrm{~kg}$ de milho nos Estados Unidos, ao passo que no Brasil para se obter $1 \mathrm{~m}$ de tecido precisamos abandonar $1 \mathrm{~kg}$ de milho". Assim, "para que se estabeleça o comércio entre eles, os Estados Unidos deverão se especializar na produção de milho, ao passo que o Brasil deverá se especializar na produção de tecidos.” (PASSOS; NOGAMI, 2006, p.525-526)

A TVC, assim como a Teoria da Vantagem Absoluta - TVA -, procura mostrar que a especialização da produção estimula o comércio internacional e favorece o consumidor. Para Prebisch, a TVC poderia ser válida para qualificar as relações entre países com o mesmo grau de desenvolvimento e a mesma capacidade competitiva, mas só trazia desvantagens para os países subdesenvolvidos. Assim, o pressuposto básico era que os países subdesenvolvidos, deixados à mercê das leis naturais do mercado, tendem a permanecer agroexportadores e a perpetuar o atraso e o próprio subdesenvolvimento.

Ensaiava-se, assim, uma nova abordagem da dinâmica do sistema centroperiferia, sob a ótica dos interesses da periferia, que incluía um plano de ação para superar o subdesenvolvimento. Esperava-se, então, da análise da relação entre centroperiferia, e de suas condicionantes para os países subdesenvolvidos, a elaboração de uma teoria do desenvolvimento. Coube a Celso Furtado amadurecer essa teoria, dar-lhe consistência e encontrar sua feição mais acabada.

A questão do desenvolvimento, no entanto, associada à questão ambiental, constituem-se temas centrais do debate político contemporâneo, quer na arena política doméstica, quer na internacional. Em geral, reduz-se a compreensão do desenvolvimento a mero crescimento econômico. Com enfoque inteiramente singular, mas, com ideias muito próximas às de Furtado, Amartya Sen, indiano ganhador do 
prêmio Nobel de Economia, em Desenvolvimento como Liberdade (2000), procura "demonstrar que o desenvolvimento pode ser visto como um processo de expansão das liberdades reais que as pessoas desfrutam". Ora, "o enfoque nas liberdades humanas contrasta com visões mais restritivas de desenvolvimento, como as que identificam desenvolvimento com crescimento" do Produto Interno Bruto - PIB -, "aumento de rendas pessoais, industrialização, avanço tecnológico ou modernização social." (SEN, 2000, p.17)

Não sem razão, o desafio do desenvolvimento, nos moldes de uma visão restritiva, e a questão ambiental, colocam-se sob o imperativo da concepção de desenvolvimento autosustentável, com exigência de preservação do meio ambiente. Contudo, as iniciativas internacionalmente conhecidas que visam implementar o desenvolvimento carecem todas de uma teoria do desenvolvimento. Esse dilema do desenvolvimento e a preservação do meio ambiente, atualmente imposto aos cientistas sociais, políticos e economistas, assim como o desenvolvimento entendido como expansão das liberdades, não se constituem objeto de nossa atual investigação.

A leitura de algumas obras de Celso Furtado, produzidas entre os anos de 19602000, evidencia-nos os conceitos recorrentes em sua produção cultural. Entretanto, o nosso objetivo é analisar a sua noção de subdesenvolvimento e o fator político na formação nacional. A análise da história política e econômica do país evidencia uma relação de interdependência entre esses dois setores da sociedade brasileira, desde o período colonial.

A noção de subdesenvolvimento de Celso Furtado remete-nos à teoria do desenvolvimento e, particularmente, à Revolução Industrial do século XVIII, ocorrida inicialmente na Inglaterra. O subdesenvolvimento é entendido como "uma situação historicamente construída" e não como "uma etapa necessária do processo de formação de uma economia desenvolvida." (FURTADO, 1961, p.184) O subdesenvolvimento brasileiro e sul-americano, e por extensão o dos estados, é resultante da industrialização.

O pensamento de Celso Furtado permite-nos ainda evidenciar o fator político na formação da identidade nacional. A formação da identidade nacional liga-se, segundo Furtado, “às aspirações de desenvolvimento das distintas áreas do imenso território" que forma o Brasil. "Na formação da nacionalidade brasileira tiveram relevância forças que conduziram ao centralismo político e outras que reivindicavam o federalismo." (FURTADO, 1999, p.46-47) De modo que a formação da nossa nacionalidade deu-se através desse movimento pendular de forças pela distribuição do poder político. 


\section{O dilema do subdesenvolvimento}

A palavra dilema refere-se a situações que se impõem sobre um indivíduo, ou sobre um conjunto de indivíduos, ou ainda, sobre uma sociedade ou nação, como necessidade de escolher entre alternativas definidoras de sua trajetória presente e/ou condicionadora de seu futuro em todas as suas dimensões. De acordo com esse conceito, a sociedade brasileira, entre os anos 1930-1970, encontrava-se rigorosamente diante de um dilema: superar o subdesenvolvimento e preservar a identidade nacional.

Entende-se mais facilmente a noção de subdesenvolvimento de Celso Furtado quando relacionada à teoria do desenvolvimento. Embora sem definir o que é uma teoria do desenvolvimento, em Desenvolvimento e subdesenvolvimento, Celso Furtado afirma que a finalidade desta teoria é "explicar, numa perspectiva macroeconômica, as causas e o mecanismo do aumento persistente da produtividade do fator trabalho e suas repercussões na organização da produção e na forma como se distribui e utiliza o produto social." (FURTADO, 1961, p.19)

Em termos gerais, a teoria do desenvolvimento, então, sempre extrapolou as categorias de análise da Economia. Para Celso Furtado, "o desenvolvimento econômico consiste na introdução de novas combinações de fatores de produção que tendem a aumentar a produtividade do trabalho". Assim, "o aumento da produtividade do trabalho e suas repercussões na distribuição e utilização do produto social constituem o problema central da teoria do desenvolvimento." (FURTADO, 1961, p.89) Daí a nossa liberdade em tomar a categoria desenvolvimento numa perspectiva mais sociológica.

$\mathrm{Na}$ perspectiva da ciência econômica neoclássica, "desenvolvimento é, basicamente, aumento do fluxo de renda real, isto é, incremento da quantidade de bens e serviços, por unidade de tempo, à disposição de determinada coletividade." (FURTADO, 1961, p.111) Em sentido estrito, “o desenvolvimento econômico é o processo de expansão do sistema produtivo que serve de suporte a uma dada sociedade." (FURTADO, 1964, p.63) Ou ainda, "é um processo de adaptação das estruturas sociais a um horizonte em expansão de possibilidades abertas ao homem". Em síntese: “o desenvolvimento não é uma simples questão de aumento de oferta de bens ou de acumulação de capital, possui ele um 'sentido'; é um conjunto de respostas a um projeto de autotransformação de uma coletividade humana". E mais, "o sentido do desenvolvimento decorrerá do projeto de autotransformação que se crie na coletividade." (FURTADO, 1969, p.18-19 - grifos do autor) 
Em sua obra Um projeto para o Brasil, Celso Furtado amplia o número de elementos essenciais ao desenvolvimento.

\begin{abstract}
Em diversas oportunidades, fizemos referências ao fato de que o desenvolvimento econômico é essencialmente uma questão de criação e assimilação de progresso tecnológico. Essa afirmação deveria ser completada por outra: o progresso tecnológico é principalmente uma questão de qualidade do fator humano. Desta forma, o problema do progresso tecnológico e o da melhoria do fator humano estarão sempre relacionados. (FURTADO, 1969, p.83)
\end{abstract}

Assim entendido, "o ponto de partida do estudo do desenvolvimento, deveria ser, não a taxa de investimento, ou a relação produto-capital, ou a dimensão do mercado, mas sim o horizonte de aspirações da coletividade em questão”. (FURTADO, 1969, p.19) O principal problema, nesse caso, é definir o campo de opções que se abre à coletividade.

Tendo exposto qual é a finalidade de uma teoria do desenvolvimento e as tentativas de conceituação do mesmo, nosso próximo passo consistirá na análise do subdesenvolvimento. Antes, porém, de apresentar a teoria do subdesenvolvimento, desenvolvida por Celso Furtado ao longo de sua trajetória intelectual, convém apresentar sua compreensão de estrutura ${ }^{4}$ subdesenvolvida.

\begin{abstract}
Aquela em que a plena utilização do capital disponível não é condição suficiente para a completa absorção da força de trabalho, ao nível de produtividade correspondente à tecnologia que prevalece no setor dinâmico do sistema. É a heterogeneidade tecnológica entre setores ou departamentos de uma mesma economia que caracteriza o subdesenvolvimento. (FURTADO, 1961, p.187)
\end{abstract}

Assim entendida, "o subdesenvolvimento não constitui uma etapa necessária do processo de formação das economias capitalistas modernas. É, em si, um processo particular, resultante da penetração de empresas capitalistas modernas em estruturas arcaicas". (FURTADO, 1961, p.184) O subdesenvolvimento é, portanto, um processo histórico autônomo; uma condição historicamente construída através das relações entre países centrais - industrializados - e os países periféricos - possuidores de matériasprimas e consumidores de produtos manufaturados.

\footnotetext{
${ }^{4} \mathrm{O}$ termo estrutura tem sua origem na filosofia marxista dos anos 60, incorporado à teoria de Furtado por influencia do pensamento cepalino. Os fundamentos do estruturalismo latino-americano são abordados por Octavio Rodríguez (2009).
} 
Ao tratar o subdesenvolvimento não como uma etapa anterior ao desenvolvimento, mas como uma condição histórica, construída e defendida politicamente, Celso Furtado questiona os fundamentos estruturais do capitalismo e da ideologia do desenvolvimento econômico dos países cêntricos. Essa perspectiva foi adotada a partir dos trabalhos da Cepal,

\begin{abstract}
Com os conceitos inovadores de centro-periferia, de subdesenvolvimento, de trocas desiguais entre produção de matérias-primas versus manufaturas no comércio internacional - contra a posição teórica dominante, das vantagens da especialização provocada pelo comércio internacional livre -, de formação de uma estrutura dual na periferia, obstáculo ao desenvolvimento e reiteração do subdesenvolvimento, constituem a base sobre a qual se assenta o trabalho de Celso Furtado. (OLIVEIRA, 1999, p.317-318)
\end{abstract}

Estabelecido que o subdesenvolvimento é por si mesmo um desequilíbrio ao nível dos fatores, isto é, da relação entre a disponibilidade de recursos e a carência de tecnologia, infere-se que as estruturas subdesenvolvidas são sistemas constituídos por setores específicos de uma determinada sociedade.

O crescimento de uma economia subdesenvolvida implica modificações estruturais. Em uma economia desenvolvida, o avanço tecnológico realiza-se de forma gradual. Na economia subdesenvolvida, no entanto, as transformações representam verdadeiras rupturas. Celso Furtado oferece-nos alguns exemplos:

\footnotetext{
A passagem da tração animal (inclusive humana) para a mecânica faz-se de um só golpe. Do carro, de fabricação artesanal e do animal de criação local, passa-se ao veículo mecânico. Dessa maneira de crescer dos países subdesenvolvidos resulta uma tendência à elevação do coeficiente de importações. (FURTADO, 1961, p.191)
}

Segundo Celso Furtado, "as três décadas que vão de 1930 a 1960 muito provavelmente passarão à História do Brasil como a etapa decisiva de desagregação da economia colonial" e também "de luta pela conquista de novos caminhos de acesso ao desenvolvimento econômico". O velho sistema, caracterizado pelo crescimento extensivo, esgotara-se. "Na situação em que se encontra presentemente o Brasil, é dever de qualquer governo realizar uma política de desenvolvimento." (FURTADO, 1962, p.64-70)

A década de 30 foi, para a economia brasileira, de significativas transformações estruturais. No intuito de defender o setor externo, o Estado brasileiro criou condições 
para uma rápida ampliação do setor industrial ligado ao mercado interno. As indústrias já instaladas aumentaram substancialmente sua rentabilidade. Contudo,

Como o desenvolvimento industrial vinha sendo feito sem a orientação de uma política, novos e graves problemas se foram acumulando. Os serviços básicos de transporte, construídos para servir à economia de exportações, não foram adaptados. O crescimento das fontes de energia, particularmente eletricidade, tampouco foi cuidado. (FURTADO, 1961, p.227-228)

$\mathrm{Na}$ década de 50, a discussão teórico-ideológica que se travava entre os partidários dos velhos interesses agroexportadores, em franca decadência, e os novos interesses vinculados ao urbano-industrial, caracterizava o debate das principais ideias econômicas da época. A controvérsia sobre o desenvolvimento econômico contrapunha, de um lado, uma corrente que defendia o liberalismo econômico, preocupada em garantir a vocação agrária do Brasil, e, de outro, uma corrente intervencionista, que pregava a industrialização deliberada do país. $\mathrm{Na}$ verdade, a polêmica entre o intervencionismo desenvolvimentista, que ganhou substância e respaldo com as teses da Cepal, e o liberalismo econômico, já se manifestara na década anterior, com Roberto Simonsen, eclético pensador e admirador do pensamento do alemão Georg List fervoroso defensor das virtudes industriais sobre a atividade agrícola - e Eugênio Gudin, de linhagem liberal, adepto da TVC, que sustentava que industrialização não era possível em países de vocação agrícola - como o Brasil.

No início da década de 60, já se podia afirmar que o impulso de crescimento da economia nacional se firmava em nosso próprio mercado interno e que o seu centro de decisões tinha suas raízes na vida nacional. Tomava-se a consciência do destino da nação, cujo símbolo maior foi a decisão de construir uma nova capital: Brasília.

Entretanto, em A pré-revolução brasileira, de 1962, Furtado observa que:

O desenvolvimento de que tanto nos orgulhamos, ocorrido nos últimos decênios, em nada modificou as condições de vida de três-quartas partes da população do país. Sua característica principal tem sido uma crescente concentração social e geográfica da renda. As grandes massas que trabalham nos campos, e constituem a maioria da população brasileira, praticamente nenhum benefício auferiram desse desenvolvimento. (FURTADO, 1962, p.14)

Do ponto de vista das massas dos países subdesenvolvidos, "o argumento da experiência histórica dos países socialistas, a exemplo da União Soviética, com sua perda de liberdade individual, foi de reduzido alcance". Isto porque "essas massas, 
porquanto não tiveram qualquer acesso às formas superiores da vida pública, não podem compreender o verdadeiro alcance do argumento". Além disso, "a suposta alternativa liberdade versus desenvolvimento rápido - pode resultar perigosa para a liberdade como aspiração coletiva, pois caberia inferir que a liberdade a que tem acesso uma minoria é paga com o sacrifício do bem-estar das grandes maiorias”. (FURTADO, 1962, p.22)

A análise do comportamento das massas dos países subdesenvolvidos permite a Furtado concluir que:

\footnotetext{
Os povos subdesenvolvidos estão dispostos a pagar um preço, mesmo muito alto, pelo desenvolvimento. E isto porque sabem - da dura experiência da miséria em que vivem - o preço altíssimo que pagam para continuar subdesenvolvidos. Poucos de nós temos consciência do caráter profundamente anti-humano do subdesenvolvimento. (FURTADO, 1962, p.22-23)
}

A situação de grandes tensões observadas no Brasil, que criou a consciência da necessidade de reformas básicas inadiáveis, decorria, em grande parte, da aceleração do desenvolvimento industrial. Para Celso Furtado, "constitui um equívoco supor que as tensões são causadas pelo sacrifício que o desenvolvimento exige da população. Desenvolvimento, por definição, significa aumento da disponibilidade de bens e serviços para fins de consumo e investimento." E acrescenta: "reconhecemos que o desenvolvimento do Brasil nos decênios recentes foi, em grande parte, o resultado de ação estatal, descontinuada e às vezes contraditória". (FURTADO, 1962, p.40-42)

A década de 60 caracterizou-se por uma lúcida tomada de consciência do problema do subdesenvolvimento. Compreendendo que "razões de ordem histórica impediram que nosso país se integrasse plenamente nas correntes do desenvolvimento econômico alimentadas pelo progresso da técnica no último século", e que "a pobreza relativa da grande maioria da população brasileira não deve ser aceita como fato de ordem natural, pois resulta de condicionantes históricos", é "natural que tenhamos colocado a questão do subdesenvolvimento no centro de todas as nossas preocupações". (FURTADO, 1962, p.72)

A experiência brasileira põe em evidência a necessidade de estudos aprofundados do processo de industrialização nas condições do subdesenvolvimento. "A tese, que prevaleceu imediatamente após a guerra, de que a industrialização constitui razão suficiente para a absorção do subdesenvolvimento, está certamente desacreditada." (FURTADO, 1972, p.8) Furtado dialoga com os principais postulados do sistema de Bretton Woods - a diplomacia do dólar e as políticas imperiais das armas. 
De acordo com a economista Maria da Conceição Tavares, "a questão do padrão monetário internacional não foi, porém, incorporada à escola latino-americana de economia política, que preferiu centrar-se no progresso técnico e na industrialização nacional como forma viável de resposta ao subdesenvolvimento". (TAVARES, 2000, p.132)

Nunca é demais lembrar, assegura Celso Furtado, "que a história do subdesenvolvimento está intimamente ligada à da revolução industrial”. A revolução industrial mostrou-se eficiente na transformação de técnicas produtivas, e na modificação nos padrões de consumo. "O subdesenvolvimento apresenta-se, assim, desde o início, como uma transformação nos padrões de consumo sem que concomitantemente se modifiquem as técnicas de produção." (FURTADO, 1972, p.9) O subdesenvolvimento é, pois uma resultante da industrialização.

Assim, "havendo tomado consciência de nosso subdesenvolvimento e havendo definido como aspiração social máxima a melhoria das condições de vida do povo, fomos levados a reformular as funções do Estado." Ora, não seria difícil demonstrar que, para desempenhar a função de promotor do desenvolvimento econômico, o Estado deveria aplicar com rigor o investimento público. "O problema básico dos países subdesenvolvidos é aumentar a eficiência de seus investimentos." (FURTADO, 1962, p.73-89) $\mathrm{O}$ aumento do índice de investimentos é função primordialmente do Estado. $\mathrm{O}$ desenvolvimento, no entanto, é para o benefício de todos.

A revisão histórica das políticas de investimentos dos sucessivos governos brasileiros permitiu a Celso Furtado concluir: "foi preciso, portanto, que decorresse todo um século desde a independência política para que o Brasil desse, sozinho, os primeiros passos na trilha do desenvolvimento econômico". Coube ao café papel básico no encerramento da economia de tipo colonial. "A economia do café, assentando em ampla base salarial, dotou o país de um núcleo de mercado interno sobre o qual se apoiaria o desenvolvimento industrial." (FURTADO, 1962, p.109) Ora, “a industrialização, em sua primeira fase, foi basicamente um processo de substituição de importações", apoiada "de forma significativa em aumento substancial dos investimentos públicos." (FURTADO, 1964, p.118-129)

A história do subdesenvolvimento consiste, fundamentalmente, no desdobramento desse modelo de economia em que o progresso tecnológico serviu muito mais para modernizar os hábitos de consumo do que para transformar os processos produtivos. A partir do momento em que entrou em declínio o sistema tradicional de 
divisão internacional do trabalho, os países subdesenvolvidos tiveram de tomar o caminho da industrialização. Primeiro, como consumidores de produtos manufaturados, depois como consumidores de tecnologias.

\section{O fator político na formação nacional}

Entre os diversos fatores que se amalgamam para a constituição da identidade nacional encontra-se, pois o fator político. Esse fator remete-nos à existência de um Estado nacional, do qual não se apartam as disputas pelo poder e pela predominância de interesses de determinados grupos, associações, organizações ou partidos políticos.

A história política do Brasil pode ser definida, ou até mesmo reescrita, por meio dos embates entre os grupos dominantes de nossa sociedade. Por essa razão, o processo político do país apresenta determinadas características que lhe são peculiares. Apenas para citar algumas, apresentamos: a questão da divisão territorial da colônia que remonta ao início da ocupação portuguesa; a questão agrária com o embate entre latifundiários e camponeses; a força política daqueles que já detinham o poder econômico - os produtores de café ou leite -; a burguesia agroexportadora versus a burguesia industrial; as novas elites e a composição do Congresso Nacional; o comportamento das bancadas no Congresso e os movimentos sociais.

O processo político em um país subdesenvolvido tende, segundo Celso Furtado, a apresentar-se sob a forma de uma "permanente luta pelo poder, entre os grupos que compõem a classe dominante, em razão da extraordinária importância que tem o controle da máquina estatal." Além disso, “em um país subdesenvolvido, todo governo forte, criado por um golpe de estado, tende necessariamente para a direita." Pelo fato mesmo de resultar de um golpe, "esse governo deverá apoiar-se na máquina existente para alcançar alguma eficácia imediata. Sem essa eficácia imediata, ele se desgastará, perderá o apoio da opinião pública, necessário para manter aquele mínimo de legitimidade sem o qual não sobreviverá". Assim sendo, "pactos são feitos inicialmente para ganhar tempo, e, por último, o são porque os objetivos iniciais já foram perdidos de vista, restando apenas o desejo de conservar o poder.” (FURTADO, 1964, p.85-88)

Se é fundamental manter um regime democrático aberto para a ação das classes assalariadas urbanas, não o é menos estender esse regime político à imensa massa camponesa. "Na maioria dos países subdesenvolvidos, e é este o caso do Brasil, a sociedade brasileira democrática permanece praticamente fechada à participação da 
massa camponesa." (FURTADO, 1964, p.89) Excluída do direito de voto por um analfabetismo compulsório, essa imensa massa quase nenhuma participação tinha na vida política do país.

Na década de 60 o Brasil vive, portanto, um período de transição. Contudo, "não conheceu o tipo de revolução burguesa que caracterizou o desenvolvimento do capitalismo industrial na Europa, até a metade do século XIX”. Esse fato se deve, pelo menos em parte, a um aspecto particular da evolução histórica do Brasil. "Os golpes dirigidos por grupos minoritários das classes dirigentes com vistas a frustrar um processo revolucionário em gestação conduzem necessariamente a situações instáveis." Mas, "como as causas estruturais das tensões continuam atuando e quiçá aumentando, o mal-estar geral conduz a dissensões dentro do próprio grupo dirigente, criando-se um clima propício a novos golpes e contragolpes.” (FURTADO, 1964, p.134-140)

As formas que assumem os processos revolucionários dependem, em boa medida, de condições históricas criadas pela própria revolução. “A configuração de uma situação pré-revolucionária não deve ser apreciada dentro de juízos de valor convencionais." Ela significa per si "que a sociedade vem atravessando vigoroso processo de desenvolvimento e que as forças que se opõem a esse desenvolvimento foram postas em xeque". De modo que "os obstáculos ao desenvolvimento não surgem em dado momento, criando-se ex abrupto a situação pré-revolucionária." (FURTADO, 1964, p.140-141)

Na década de 70, em Análise do modelo brasileiro, Celso Furtado se mostrava convencido de que o Brasil constitui um caso singular para o estudo do subdesenvolvimento. Isso se infere de sua análise do setor industrial, da condição da agricultura e da população na zona rural, e da participação do Estado no desenvolvimento:

\footnotetext{
O Estado tem ampla participação nas decisões econômicas e constitui, de longe, a fonte principal do processo de acumulação; mas, como a tecnologia que se utiliza é importada em sua quase totalidade, a capitalização nos setores mais dinâmicos da economia faz-se principalmente em beneficio dos grupos estrangeiros. O principal problema com que se defronta o país é o de gerar fontes de emprego para sua numerosa e crescente população, grande parte da qual vegeta em setores urbanos marginalizados ou na agricultura de subsistência. (FURTADO, 1972, p.7-8)
}

Celso Furtado sustenta que o desenvolvimento exige dos que dirigem o país, de modo inadiável, reforma de estruturas, como condição fundamental para o efetivo 
estado de libertação do Estado, da Nação, da sociedade e dos cidadãos. O esforço para a mudança de estruturas não deve se limitar às reformas superficiais das estruturas vigentes. A mudança de estruturas nos países subdesenvolvidos supõe, indubitavelmente, a mudança de estruturas nos países desenvolvidos.

O processo a ser desencadeado em vista da mudança de estruturas pressupõe uma intensa atividade política. Entretanto, "modificar de forma significativa a estrutura de um sistema em prazo relativamente curto não é empresa fácil. Os recursos dos que resistem à mudança social são pelo menos tão férteis quanto a imaginação dos reformadores." (FURTADO, 1969, p.14) Daí a seguinte constatação:

Existe no sistema econômico deste país uma deformação estrutural que se traduz no perfil da demanda global. Essa deformação é responsável pela lenta penetração do progresso tecnológico em nossa economia e pela escassa difusão dos frutos dos aumentos de produtividade. (FURTADO, 1969, p.15)

Não obstante, "a existência de um Estado nacional introduz uma dimensão política nos cálculos econômicos". Além disso, "a emergência precoce de um sistema político criou condições para que se realizassem transferências inter-regionais de população e renda no vasto território que veio a constituir o Brasil.” (FURTADO, 2000, p.7) A Nação brasileira constitui-se no entrelaçamento de fatores políticos e econômicos inter-relacionados.

No plano político, a formação da nacionalidade brasileira é contemporânea e, ao mesmo tempo, resultante de um embate entre "forças que conduziam ao centralismo político e outras que reivindicavam o federalismo." O federalismo é expressão da "ideia de que a organização política deve basear-se na solidariedade e na cooperação, e não na compulsão." O centralismo, no período monárquico, limitava-se ao quadro institucional; no período Vargas, abriu caminho à completa unificação do mercado interno; no período dos governos militares, fundou-se em uma visão do país que dava excessiva ênfase à ideia de segurança nacional. Ele é "instrumental na fase de formação da nacionalidade e, até certo ponto, na de construção de um sistema econômico suficientemente integrado para que a tecnologia moderna fosse amplamente absorvida." A "consciência de unidade nacional coexiste com o senso de identidade que se definiu historicamente em cada região particular. A identidade do brasileiro tem raízes em sua inserção regional”. Assim, “a pulsação centralismo-federalismo deve, portanto, ser situada na história tendo-se em conta esses dois traços fundamentais de nossa cultura, 
que são a consciência de unidade nacional e o irredutível da identidade regional." (FURTADO, 1999, p.45-50)

Na dimensão econômica, "a política de substituição das importações conduziu a classe política a uma opção política de elevado custo econômico.” No caso da crise da borracha na região amazônica, "a importação da borracha a baixo preço teria sido a solução indicada pela lógica dos mercados. Evitar o esvaziamento demográfico da região era uma opção política de elevado custo econômico.” Da mesma forma, quando foi instalada a indústria automobilística brasileira, uma região como o Nordeste, que desfrutava de um saldo significativo em seu comércio exterior, o país "teve de renunciar à importação de veículos para adquirir um produto nacional de preço mais alto e nem sempre da mesma qualidade. Era uma decisão política, portanto fora do alcance da racionalidade dos mercados". Tais fatores expressavam o interesse de uma industrialização nacional, resultante de "visão nacional, isto é, política". (FURTADO, 2000, p.7)

No plano social, essa opção política também revela o seu custo. Segundo Celso Furtado, "o que permitia aos brasileiros conviver com as gritantes injustiças sociais era o intenso dinamismo da economia. Muitos observadores descobriram nesse dinamismo uma fonte de legitimidade para um sistema de poder que gerava tantas injustiças." (FURTADO, 1992a, p.12) O preço social que estava sendo pago pelo desenvolvimento era exorbitantemente elevado.

Nas últimas décadas do século $\mathrm{XX}$, as mudanças econômicas e políticas, em âmbito internacional, obrigaram a sociedade brasileira a escolher entre alternativas igualmente difíceis e de elevado custo social. As empresas transnacionais, num curto período de tempo, passaram a controlar os processos produtivos, de distribuição e, por vezes, de consumo de inúmeras mercadorias. Contudo, “o esvaziamento dos sistemas decisórios nacionais será de consequências imprevisíveis para a ordenação política de vastas regiões do mundo, em particular para os países subdesenvolvidos." (FURTADO, 2000, p.7-8) Algumas empresas transnacionais conseguiram acumular capital e poder de influência superior à capacidade de muitos estados nacionais, quer quando tomados isoladamente, quer mesmo em conjunto.

O elemento mais significativo de aproximação do capital estrangeiro com as elites nacionais históricas está na preocupação de dar legitimidade ao sistema de poder mediante a tradução, em linguagem de objetivos nacionais, dos interesses dos grupos dirigentes - industriais ou financeiros. "O nacionalismo surge, assim, como técnica de 
legitimação." (FURTADO, 1972, p.36) Em países subdesenvolvidos, em especial, a aliança com um "regime de força" traduz-se em segurança para os negócios dos investidores estrangeiros.

As transformações ocorridas no sistema capitalista e na ordem política internacional, em particular, na segunda metade do século XX, repercutem no processo de formação e/ou consolidação do Estado. "Como as possibilidades de integração social e territorial do país dependiam do dinamismo do modelo econômico, a inviabilização deste acarretou a anulação dos mecanismos que possibilitariam o avanço na construção do Estado.” (SAMPAIO, 2000, p.64) Trata-se da construção de um Estado capaz de superar as dicotomias atrasado-moderno, inclusão-exclusão, concentração de rendaincorporação das massas, elitismo político-ampliação da participação popular, que impunham enormes sacrifícios à maioria da população e tornavam a nação extremamente vulnerável aos movimentos do capital internacional.

As modificações estruturais ocorridas no centro do sistema capitalista, na década de 70 , devem ser tidas em conta em qualquer tentativa de identificar as tendências evolutivas atuais do conjunto do sistema capitalista. Alguns elementos precisam ser considerados, tais como:

\footnotetext{
Em primeiro lugar, é necessário ter em conta que o processo de unificação [das economias nacionais] abriu o caminho a uma considerável intensificação do crescimento do próprio centro. Em segundo lugar, ampliou-se consideravelmente o fosso que já separava o centro da periferia do sistema, o que em grande parte é simples consequência da intensificação do crescimento no centro. Em terceiro lugar, as relações comerciais entre países cêntricos e periféricos, mais ainda do que entre países cêntricos, transformaram-se progressivamente em operações internas das grandes empresas. (FURTADO, 1974, p.44)
}

Para Celso Furtado, "sobra dizer que a industrialização que atualmente se realiza na periferia sob o controle das grandes empresas é processo qualitativamente distinto da industrialização que, em etapa anterior, conheceram os países cêntricos." Pois, "o dinamismo econômico no centro do sistema decorre do fluxo de novos produtos e da elevação dos salários reais que permitem a expansão do consumo de massa." Em contraste, "o capitalismo periférico engendra o mimetismo cultural e requer permanente concentração de renda a fim de que as minorias possam reproduzir as formas de consumo dos países cêntricos." (FURTADO, 1974, p.45) O controle das empresas transnacionais, nos países periféricos, se exerce sobre empresas locais, ou mesmo sobre estados pequenos e fracos. 
Em $O$ mito do desenvolvimento econômico, Celso Furtado observa que

\begin{abstract}
a evolução do sistema capitalista caracterizou-se por um processo de homogeneização e integração do centro, um distanciamento crescente entre o centro e a periferia e uma ampliação considerável do fosso que, dentro da periferia, separa uma minoria privilegiada e as grandes massas da população. A intensidade do crescimento no centro condiciona a orientação da industrialização na periferia, pois as minorias privilegiadas dessa última procuram reproduzir o estilo de vida do centro. Em outras palavras: mais intenso o fluxo de novos produtos no centro, mais rápida a concentração da renda na periferia. (FURTADO, 1974, p.46)
\end{abstract}

As complexas relações que existem entre os governos dos países cêntricos, entre esses governos e as grandes empresas, entre eles e as instituições internacionais, dificilmente podem ser percebidas com clareza. As empresas, por maiores que sejam, são organizações relativamente simples no que respeita aos seus objetivos. O Estado, numa sociedade em que grupos concorrentes competem e quase sempre dividem de alguma forma o poder, constitui uma instituição muito mais complexa, de objetivos menos definidos e cambiantes.

Um sistema econômico nacional não é outra coisa senão a prevalência de critérios políticos sobre a lógica dos mercados na busca do bem-estar coletivo. (FURTADO, 2000, p.8) O mesmo argumento pode ser formulado na linguagem dos objetivos ou interesses nacionais. Isto é, os interesses nacionais precedem às pretensões regionais, na arena política doméstica, em favor de uma política de interdependência econômica. Uma vez mais, entende-se, pois, que tomam-se decisões políticas contrárias à lógica dos mercados, porém, em nome da coletividade e do nacional.

Nessa perspectiva, fortalece-se uma determinada ideologia de identidade nacional, de formação de uma nacionalidade, ou mesmo de estímulo à expressão de um sentimento nacional. Não obstante, tal opção política resulta em enfraquecimento das potencialidades regionais, ou em valorização de uma região do país em prejuízo de outras.

Constata-se, no entanto, a fragilização de um projeto do crescimento econômico.

$\mathrm{Na}$ lógica da ordem econômica internacional emergente parece ser relativamente modesta a taxa de crescimento que corresponda ao Brasil. Sendo assim, o processo de formação de um sistema econômico já não se inscreve naturalmente em nosso destino nacional. (FURTADO, 1992a, p.13) 
Plínio de Arruda Sampaio atribui à elite dirigente esse equívoco no modo de inserção da economia brasileira no mercado internacional.

Acuada entre a necessidade de enfrentar as forças dominantes no sistema capitalista para prosseguir o processo de construção do seu Estado ou renunciar a ele, a elite ficou sem capacidade de reação e acabou tendo de aceitar as imposições dos núcleos centrais do sistema econômico e político da ordem capitalista mundial. (SAMPAIO, 2000, p.65)

O Estado nacional insiste na estratégia de coordenação, de fiscalização e, por vezes, de tributação das atividades econômicas que se desenvolvem no interior de suas próprias fronteiras. "Na lógica das empresas transnacionais, as relações externas, comerciais ou financeiras, são vistas, de preferência, como operações realizadas no âmbito interno de empresas." Nessas circunstâncias, já não se contará com a integração das economias regionais e a formação do mercado interno como motor do crescimento. "A alternativa consiste em apoiar-se, de preferência, no mercado internacional, o que significa depender da dinâmica das empresas transnacionais." (FURTADO, 2000, p.910) Ora, o estilo de desenvolvimento que estas impõem caracteriza-se por uma margem crescente de desemprego estrutural.

É natural que esses efeitos se manifestem agravados em países que interromperam a formação do mercado nacional para privilegiar a integração internacional. A esse respeito, Celso Furtado diz que:

\begin{abstract}
Nos países desenvolvidos que empreenderam a integração dos espaços econômicos respectivos, as transferências regionais de recursos, condicionadas a parâmetros culturais, se estimam em dezenas de bilhões de dólares; é o que está acontecendo nos países ibéricos depois de sua incorporação à União Europeia, e, em escala ainda maior, nas províncias que formavam a antiga Alemanha Oriental. (FURTADO, 2000, p.10)
\end{abstract}

Com efeito, tratando-se de uma economia subdesenvolvida, a exaustão dos efeitos provocados pela integração internacional indiscriminada terá, necessariamente, resultados mais expressivos no plano social, a exemplo da gestação de conflitos regionais. Além disso, os reflexos no campo político virão sem demora.

De qualquer modo, afirmou-se que

A regionalização dos interesses políticos, que se manifesta tão fortemente por toda parte, foi contida no passado, em seus efeitos centrífugos, pelo exercício de um poder hegemônico regional, o qual foi sendo substituído pela interdependência dos interesses econômicos que emergiu com a formação de um sistema nacional. (FURTADO, 2000, p.10) 
Como resultado, a liberdade de deslocar-se territorialmente em busca de emprego, de aperfeiçoamento cultural, de abrir ou expandir negócios, ter acesso a mercado mais amplo e dinâmico, constituem fatores que emprestaram um conteúdo real à ideia de unidade nacional.

Nas décadas de 30, 40 e 50, quando da instalação do parque industrial no país, "a migração interna permitiu o barateamento da mão-de-obra nas áreas que absorviam o essencial dos investimentos industriais. Concentrava-se a renda, mas ao mesmo tempo cresciam os investimentos e o mercado interno." No início do século XXI, "em que se pretende derivar o dinamismo da integração internacional, o que importa é fomentar o espírito competitivo em atividades com vocação para a exportação.” (FURTADO, 2000, p.1) Nessas circunstâncias, as condições regionais de competitividade podem ser percebidas em níveis pouco ou quase nada equivalentes. Como consequência, constatam-se o crescimento regional desigual, a concentração de renda e, por vezes, a relativização de valores no que tange à preservação da unidade nacional.

Plínio de Arruda Sampaio propõe "pensar o Brasil e o mundo fora dos parâmetros estabelecidos." (SAMPAIO, 2000, p.73) Como a elite brasileira renunciou ao projeto de construção nacional, o desafio, logicamente, não se dirige a ela e sim a um conjunto formado por segmentos sociais bastante diversos. O primeiro desafio posto para as classes populares consiste em "pensar o Brasil e o mundo com liberdade" (SAMPAIO, 2000, p.73), a fim de "deslocar o curso da civilização da lógica dos meios a serviço da acumulação para uma lógica dos fins em função do bem estar social, do exercício da liberdade e da cooperação entre os povos." (FURTADO, 1992a, p.76) O segundo desafio consiste em "derrotar a mentalidade colonizada da elite e dos segmentos contaminados por ela." Isto porque "a mentalidade colonizada provoca o sentimento de inferioridade, a ideia enganosa de que não temos condições de vencer o subdesenvolvimento sem a ajuda do pensamento formulado no estrangeiro; sem os recursos técnicos concentrados nesses países." (SAMPAIO, 2000, p.73-74) O terceiro desafio dirige-se aos movimentos e, mais especialmente, aos partidos que representam os interesses e visões de mundo das classes populares. "Trata-se de conquistar o poder político do Estado", transformando-o em um instrumento de democracia, de desenvolvimento econômico e de promoção da equidade social. Trata-se, pois, "de montar um estado eficaz." (SAMPAIO, 2000, p.75)

A construção de um Estado eficiente, cujo comportamento de seus cidadãos seja pautado pelo sentido de país, requer a consciência de sua própria história. 


\begin{abstract}
Durante três séculos a economia brasileira baseara-se na exploração extensiva de recursos em grande parte não renováveis: da exploração florestal dos seus primórdios até a grande mineração, passando pelo uso destrutivo dos solos nos vários ciclos agrícolas, por muito tempo fomos um caso exemplar do que se conhece como "desenvolvimento não sustentável". É somente no século atual $[\mathrm{XX}]$ que a economia brasileira deixa de fundar seu dinamismo na depredação de recursos naturais e passa a apoiá-lo na assimilação de avanços tecnológicos e na acumulação de capital reprodutível. (FURTADO, 1992b, p.58 - grifos do autor)
\end{abstract}

Sem lugar a dúvida, a evolução da economia brasileira caracteriza-se pelo enfrentamento de inúmeros desafios, entre os quais encontra-se o centralismo econômico, que só é possível ser detido mediante ação política. Para Furtado, "somente a vontade política pode evitar que a difusão da racionalidade econômica venha transformar um tecido social diversificado num amálgama de consumidores passivos. $\mathrm{E}$ essa vontade política entre nós é inseparável do federalismo." Assim, "o problema institucional maior que se coloca à sociedade brasileira é exatamente esse de estimular a capacidade criativa em todos os segmentos.” (FURTADO, 1999, p.53)

Em suma, "preservar nossa identidade cultural e unidade política em um mundo dominado por grupos transnacionais que fundam seu poder no controle da tecnologia, da informação e do capital financeiro" constitui "desafio com que nos deparamos." O enfrentamento de tal desafio exige "refletir seriamente sobre a situação de perda de rumo em que nos encontramos" (FURTADO, 1992b, p.58), e proceder seriamente à análise do modelo brasileiro de desenvolvimento.

\title{
Considerações finais
}

A análise da realidade econômica dos países subdesenvolvidos permite a Celso Furtado concluir que subdesenvolvimento é um fenômeno historicamente construído, assim como as relações de poder, de gênero etc. A revolução industrial do século XVIII, enquanto expandia os seus benefícios para a economia inglesa, aprofundava a diferença de condições entre os outros países da Europa. Os países recém-nascidos durante o processo de descolonização, nos anos 60, tiveram suas economias e populações condenadas ao subdesenvolvimento.

O caminho adotado pelos atuais países para o fortalecimento de suas economias se mostra como o grande fracasso de século $\mathrm{XX}$ - a exploração predatória dos recursos naturais, o esgotamento das potencialidades humanas em favor do crescimento econômico, o desmatamento de grandes áreas realizado de forma irracional, a poluição 
do ar e do mar. A simples adoção do modelo, outrora protagonizado pelos países desenvolvidos, conduzirá os países subdesenvolvidos à mera reprodução de padrões de consumo dos países centrais, sendo as elites dos países periféricos responsáveis pela reprodução da dependência.

No interior dos países subdesenvolvidos, e também nos países centrais, os diversos grupos de interesses - os movimentos sociais, as organizações nãogovernamentais, as organizações financeiras, os grupos ambientalistas, os governos locais e regionais, as associações comerciais e sindicatos etc. - travam verdadeiras lutas pelo poder, pois a busca incessante pelo controle, ainda que parcial, da máquina estatal, pode traduzir-se em benefícios políticos e econômicos.

Assim, em uma sociedade marcada por profundas distorções regionais e estruturais, os efeitos de uma não intervenção do Estado nas atividades econômicas irão certamente muito além do abandono de uma política econômica, pois poderão produzir inúmeras convulsões sociais. Dessa maneira, faz-se necessário um Estado nacional capaz de introduzir uma dimensão política nos cálculos econômicos.

Atualmente, a economia, a política e a sociedade brasileira respiram novos ares. Portanto, não nos é mais permitido navegar às cegas. Um projeto nacional de desenvolvimento precisa conjugar uma vontade política fundada em amplo consenso social com condições "objetivas" de realização de um projeto de desenvolvimento capaz de assegurar o bem-estar social e, ao mesmo tempo, a preservação da identidade nacional. 


\begin{abstract}
This article aims to analyze the notion of underdevelopment and the political factor in national training, supported in the thoughts of Celso Furtado. Holder of experience in the fields of politics (Minister of Planning) and public administration (Sudene director), Furtado understands underdevelopment as a historical phenomenon resulting from the English industrial revolution of the eighteenth century; not as a stage backward economies need to pass through and will eventually leave. In Brazil, the awareness of underdevelopment in the $60 \mathrm{~s}$, changes the course of politics and the economy in the subsequent decades. The thought of Celso Furtado allows us to show - besides a deep analysis of the relationship between economics and politics - the political factor in the formation of national identity.
\end{abstract}

Key Words: Underdevelopment; Political factor; National formation.

\title{
Referências
}

FURTADO, Celso. Formação econômica do Brasil. São Paulo: Ed. Nacional, 1959.

FURTADO, Celso. Desenvolvimento e subdesenvolvimento. Rio de Janeiro: Fundo de Cultura, 1961.

FURTADO, Celso. A pré-revolução brasileira. Rio de Janeiro: Fundo de Cultura, 1962.

FURTADO, Celso. Dialética do desenvolvimento. Rio de Janeiro: Fundo de Cultura, 1964.

FURTADO, Celso. Um projeto para o Brasil. Rio de Janeiro: Ed. Saga, 1969.

FURTADO, Celso. Análise do "modelo" brasileiro. Rio de Janeiro: Civilização Brasileira, 1972.

FURTADO, Celso. O mito de desenvolvimento econômico. Rio de Janeiro: Paz e Terra, 1974.

FURTADO, Celso. Brasil: a construção interrompida. Rio de Janeiro: Paz e Terra, 1992a.

FURTADO, Celso. Globalização das estruturas econômicas e identidade nacional. Estudos avançados, v. 6, n. 16. São Paulo: Edusp, p.55-64, 1992b.

FURTADO, Celso. O longo amanhecer: reflexões sobre a formação do Brasil. Rio de Janeiro: Paz e Terra, 1999.

FURTADO, Celso. O fator político na formação nacional. Estudos Avançados, v. 14, n. 40. São Paulo: Edusp, p.7-11, 2000. 
GUIMARÃES, Juarez. A trajetória intelectual de Celso Furtado. In: TAVARES, Maria da Conceição (org.). Celso Furtado e o Brasil. São Paulo: Fundação Perseu Abramo, 2000 .

OLIVEIRA, Francisco. Celso Furtado: economia. São Paulo: Ática, 1983.

OLIVEIRA, Francisco. Celso Furtado: Formação Econômica do Brasil. In: MOTA, Lourenço Dantas (org.). Introdução ao Brasil: um banquete no trópico. São Paulo: SENAC, 1999, p.317-333.

RODRÍGUEZ, Octavio. O estruturalismo latino-americano. Rio de Janeiro: Civilização Brasileira, 2009.

SAMPAIO, Plínio Arruda. Dilema e desafios postos para a sociedade brasileira. Estudos Avançados, 14 (40), p.64-76, 2000.

SEM, Amartya. Desenvolvimento como liberdade. Tradução de Laura Teixeira Motta, 6 ed. São Paulo: Companhia das Letras, 2000. 